\title{
ÇÖZÜM ODAKLI KISA SÜRELİ TERAPIYE KISA BİR BAKIŞ
}

\section{SOLUTION FOCUSED BRIEF THERAPY: A BRIEF OVERVIEW}

\author{
Ümüt ARSLAN ${ }^{1}$ GÖZDE GÜMÜŞÇAĞLAYAN ${ }^{2}$
}

\begin{abstract}
Başvuru Tarihi: 17.02.2018 $\quad$ Yayına Kabul Tarihi: 28.06.2018 $\quad$ DOI: 10.21764/maeuefd.396228
Özet: Çözüm Odaklı Kısa Süreli Terapi (ÇOKST) 1980’li yıllarda De Shazer, Berg ve arkadaşlarının uzun çalışmaları sonucunda Amerika Birleşik Devletleri'nde ortaya çıkmıştır. Tüme varım şeklinde ortaya çıkan ÇOKST, psikolojik danışma alanında başarılı olarak kendine yer edinmiştir. ÇOKST yapılandırmacı ve postmodern bir psikoterapi yaklaşımıdır. Danışanın kendi gücüne ve danışanla danışman arasındaki terapötik iş birliğine odaklanmaktadır. Probleme odaklanmadan danışanın amacına yönelik çözüm inşa etme süreçleriyle ilgilenmektedir ve bunlar bir konsept içinde geliştirilen çözüm odaklı sorular ile uygulanmaktadır. Probleme odaklanan danışma yaklaşımlarının ağırlıklı olduğu eğitim programlarından mezun olan psikolog ve psikolojik danışmanlar için ÇOKST'nin özümsenmesi zor olabilmektedir. Psikolojik danışma uygulamalarında, problem odaklı yaklaşımını uygularken ÇOKST sorularının kullanması en yaygın karşılaştığımız problemlerden birisidir. $\mathrm{Bu}$ kapsamda, bu makalenin amacı ÇOKST'nin tarihsel ve felsefi duruşuna atıf yaparak felsefesini, temel prensiplerini, danışma sürecinde yer alan temel soruları (örneğin: mucize, derecelendirme, istisna, baş etme) ve uygulamada dikkat edilmesi gereken

Abstract: Solution Focused Brief Therapy (SFBT) has emerged in the 1980's as a result of De Shazer, Berg and colleagues' studies in the United States. SFBT, was emerged as inductive method, has become one of the successful counseling techniques. SFBT is a constructivist and post-modern psychotherapy approach. It emphasizes client's own power and therapeutic cooperation with counselor. Focuses on the process of building a solution for the client's purpose without discussing problems, and they are applied by solution-focused questions in a structure. Because counselors and psychologists are graduate from problem-focused therapist training programs, it could be difficult to digest SFBT for therapists. For this reason, using SFBT questions in a problem-focused counseling practice is one of the most common problems. In this context, the aim of this study is to explain philosophy, basic principles, basic questions in the counseling sessions (example: miracle, scale, exception, and coping), and crucial points in a practice of the SFBT with referring its historical and philosophical views to counselor trainees, counselors, and counselor educators.
\end{abstract} noktaları psikolojik danışmanlara, psikolojik danışman adaylarına ve psikolojik danışmanlık alanında eğitim veren öğretim üyelerine açıklamaktır.

Anahtar Kelimeler: çözüm odaklı kısa süreli terapi, post modern yaklaşımlar
Keywords: solution focused brief therapy, postmodern approaches

\section{Giriş}

Amerika Birleşik Devletleri’nde ortaya çıktıktan sonra, psikolojik danışmada kullanılan terapi modelleri arasına yer almayı başaran çözüm odaklı kısa süreli terapi (ÇOKST), adını

1 Sorumlu Yazar: Dr. Öğr. Üyesi, İzmir Demokrasi Üniversitesi, Eğitim Fakültesi, Eğitim Bilimleri Bölümü, umut.arslan@idu.edu.tr, Orcid No: 0000-0002-3611-9607

2 Arş. Gör., Mehmet Akif Ersoy Üniversitesi, Eğitim Fakültesi, Eğitim Bilimleri Bölümü, ggumuscaglayan@mehmetakif.edu.tr, Orcid No: 0000-0002-1864-7641 
çözüm inşa etmeye odaklanmasından ve kısa süreli tedaviye vurgu yapmasından almaktadır. Literatür incelendiğinde ÇOKST'nin yapılandırmacı ve post-modern bir psikoterapi yaklaşımı olduğu; danışanın gücüne ve danışanla danışman arasındaki terapötik işbirliğinin pozitif ve yapıcı yönünü vurguladığı görülmektedir (De Jong ve Berg, 1997; De Shazer ve Berg, 1992; Groot, 2002; Hoyt ve Berg, 1998). Diğer birçok terapi modelinin aksine ÇOKST, tümdengelim metodu yerine tümevarım metodunun kullanılmasıyla gelişmiştir (Berg ve Miller, 1992). ÇOKST, Watzlawick, Weakland ve Fisch'in (1974) psikolojik danışma sürecinde danışanların getirdikleri sorunları çözebilmek amacıyla süreçte her zaman problemi incelemenin gerekli olmadığını belirten çalışmalarının devamı olarak; De Shazer, Berg ve arkadaşları tarafından Amerika Birleşik Devletleri'nin Milwaukee şehrinde çalıştıkları bir aile terapisi merkezinde geliştirilmiştir (De Shazer, 1985). ÇOKST, 20 yıldan fazla bir zaman içerisinde uygulanan binlerce saatlik terapi seanslarındaki başarılı uygulamaların birikimiyle oluşturulmuştur (De Shazer ve diğ., 2007). Modelin gelişim sürecinde defalarca çözümlenerek uygulanması sayesinde oldukça tutarlı bir model haline gelmiştir. Ancak bu terapi modelinin uygulanması konusundaki çeşitli zorlukları ve soru işaretlerini irdeleyen birçok araştırma yer almaktadır. Ayrıca bu araştırmalar, ÇOKST'ye ek olarak çözüme yönelik terapi (solution-oriented therapy) modelinin de gelişmesine katkı sağlamıştır.

ÇOKST sürecinde danışan, kendisi için en iyiyi bilen uzman olarak kabul edilmektedir (Groot, 2002). Bu terapi sürecinde danışman, danışanın kendi problemini çözebilecek yeterli kaynaklara sahip olduğuna inanmaktadır. Onun güçlü yanlarına ve onun isteklerine odaklanmaktadır ve böylece danışman ile danışan arasında, danışanın potansiyelini en üst seviyeye çıkarabilmesini amaçlayan terapötik etkileşim oluşmaktadır. ÇOKST'nin geleneksel terapi yöntemlerinden ayrıldığı en önemli noktalardan birinin, bugün ve gelecek için geçmişten uzak duran tutumu olduğu görülmektedir. Ek olarak, geleneksel terapi yaklaşımları danışanda değişim yaratmanın zor olduğunu belirtirken, ÇOKST danışanda değişim yaratmanın sürekli olabileceğini vurgulamaktadır (Groot, 2002).

Literatür incelendiğinde ÇOKST'yi açıklayan kavramlar 1şığında yapılan çalışmaların diğer yaklaşımlara göre biraz daha sınırlı kaldığı görülmektedir (Bavelas ve diğ., 2013). Psikolojik danışma konusunda yıllık ortalama 1600 çalışma yapılırken, ÇOKST konusunda yapılan çalışma sayısı 130 civarındadır (Macdonald, 2013). Ayrıca, Türkiye'de psikolog ve psikolojik danışman olmak için yüksek lisans derecesinde eğitim alma zorunluluğunun olmaması bilgi, yetenek ve deneyim açısından birçok sıkıntıyı beraberinde getirirken, ÇOKST uygulamasında da sorunların daha çok ortaya çıkmasına sebep olabilmektedir (Bavelas ve diğ., 2013; Eriksen ve McAuliffe, 2003). Danışmanların yeterlilikleri ÇOKST uygulamasında çok önemlidir. Bu sebeple Amerika Birleşik Devletleri'nde akredite olan eğitim merkezleri ÇOKST eğitimini sadece klinik alanda (psikolog, psikolojik danışman, sosyal hizmet uzmanı veya psikiyatrist) uygulamalı yüksek lisans derecesine sahip olan kişilere vermeyi tercih etmektedir (Bavelas ve diğ., 2013). 
Bu kapsamda, bu makalenin amacı çözüm odaklı kısa süreli terapinin tarihsel ve felsefi duruşuna atıf yaparak, psikolojik danışmanlara, psikolojik danışman adaylarına ve psikolojik danışmanlık alanında eğitim veren öğretim üyelerine uygulamada dikkat edilmesi gereken noktalar hakkında bilgi vermektir. Çünkü ÇOKST, felsefesinden anlamına, sorularından uygulamasına diğer terapi modelleriyle farklı bir yaklaşıma sahiptir ve bu uygulama modelinin diğer problem odaklı modellerle birleştirilmesinde veya birlikte uygulanmasında sorunlar çıkabilir (Bavelas ve diğ., 2013). Bu sorunlar ve danışma sürecinde ortaya çıkan sınırlılıklar, ÇOKST'nin yeterliliklerinden ziyade genellikle uygulamalardaki yanlışlıklar nedeniyle oluşabilmektedir (De Shazer ve Dolan, 2012). ÇOKST uygulamaları, problem odaklı yaklaşımların uygulamalarından uzakta kendi içinde dengelidir ve başarısı çözüme odaklı olması kadar, probleme odaklı çalışmamasından kaynaklanmaktadır (DeJong ve Berg, 1998).

\section{Tarihsel Süreç}

Çözüm odaklı kısa süreli terapi (ÇOKST) De Shazer, Berg ve arkadaşları tarafından Milwaukee'deki Aile Terapi Merkezinde uzun uygulamalar sonucunda ortaya çıkmıştır (De Shazer, 1985). De Shazer, Berg ve arkadaşları Milwaukee'deki toplantılarında terapi seanslarında işe yarayan teknikleri uzun yıllar tartışmışlar; ÇOKST sürecinde yer alan yöntemleri kullanarak onları geliştirmişlerdir (De Shazer, 1985). Bu çalışmaların sonuçları şu şekilde özetlenebilir: (a) psikolojik danışma sürecinde danışmanların çözüme yönelik konuşmaları, ilerleyen oturumlarda elde edilecek olan başarı oranlarını arttırmaktadır ve (b) danışanların hali hazırdaki başarıları hakkında konuşmalarının ve bu başarıları diğer problemlere nasıl transfer edebilecekleri üzerine tartışmalarının oldukça olumlu sonuçlar ortaya çıkarmaktadır (DeJong ve Berg, 1998). Milwaukee çalışanları yaptıkları çalışmaların sonucunda terapi sürecinde çözüme odaklanma durumunun önemini vurgulayarak ÇOKST'yi tanımlamışlardır (Berg ve Miller, 1992).

\section{Çözüm Odakı Kısa Süreli Terapinin Felsefesi ve Önemi}

Sirler, Lipchik ve Kowalski'nin (1993) belirttiği gibi, ÇOKST sürecinde problemin kökeni yerine sorunun yok edilmesi amacıyla şu an ne yapılması gerektiği konusu önemsenmektedir. Bütün psikologların ve psikolojik danışmanların geleneksel problem odaklı terapi yöntemlerini öğrenerek mesleklerine hazırlanmış olmaları nedeniyle, onların terapi süresinde sadece çözüme odaklanmaları zor olabilmektedir. Danışma sürecinde problemlerin temeline inen ve danışanın, problemi daha ayrıntılı bir şekilde anlatması için onu cesaretlendiren sorular ÇOKST'de tercih edilmemelidir. ÇOKST'de, problemin anlatılması karşısında danışman (a) yansıtma veya kişiselleştirme yapmaz, (b) detaylandırmak için soru sormaz ve (c) diğer sözlü

veya sözlü olmayan danışma tekniklerini kullanarak problemi daha detaylı anlatması için olumlu pekiştireç vermez.

Birçok ÇOKST kitabında bulunan ve bu terapinin özünü anlatan temel prensipler şunlardır:

- $\quad$ Eğer kırık değilse, tamir etme.

- $\quad$ Eğer işe yarıyorsa, daha fazla yap. 
- $\quad$ Eğer işe yaramıyorsa, farklı şeyler yap.

- $\quad$ Küçük adımlar büyük değişimlere öncülük edebilir.

- Çözümün problem ile doğrudan bağlantılı olması gerekmiyor.

- Çözüme ulaşılabilmesi için kullanılması gereken dil problemi tanımlamak için ihtiyaç olandan farklıdir.

- Her zaman problem olmaz, her zaman istisnalar vardir.

- $\quad$ Gelecek yaratılabilir ve tartışılabilir (De Shazer, 1985; De Shazer ve Dolan, 2012).

Psikologların veya psikolojik danışmanların bu terapiyi içselleştirmeden uygulaması, sadece çözüm odaklı terapi sorularını sormalarından ileriye gitmeyebilir. Asay ve Lambert'in (1999) belirttiği danışmada etkili olan faktörler göz önüne alındığında; danışmanların danışanını anlamadan (\%40), danışanla terapötik ilişki kuramadan (\%30), onu geleceğe ve danışmaya geldiği için ümitlendirmeden (\%15), onu sadece teknik ile başarıya ulaştırma şansı (\%15) çok düşüktür. Çözüm odaklı veya problem odaklı yaklaşımların, psikolojik danışmaya etkisi sadece \%15'tir. Diğer faktörlerdeki (danışan, terapötik ilişkiler ve ümit) yaşanan sınırlılıklar, psikolojik yaklaşımın kuramsal farklılıklarından ziyade psikolojik danışmanın yeterlilikleriyle ilişkilidir (Karaca ve İkiz, 2014). ÇOKST’yi özümsemiş olan danışman, danışanı çözüm odaklı perspektifte anlamaktadır; onun önceki problemlerinin çözüm yollarını nasıl bulduğunu ve gelecekte bunu nasıl tekrarlayabileceğini danışanla birlikte konuşup, istisnaları geleceğe ümitle bakan bir ölçekte tartışabilmektedir (Bavelas ve diğ., 2013). Danışmanların ÇOKST’yi anlamadan, bilmeden, özümsemeden uygulamaya çalışması, problem odaklı terapide sadece çözüm odaklı sorularını kullanmalarına yol açmaktadır. Bu da doğal olarak danışma sürecinin tıkanmasına, işlevsiz olmasına ve danışmanın, danışanla şimdiye ve geleceğe odaklanması yerine geçmişteki problemlerde takılı kalınmasına neden olmaktadır. Sonuç olarak, sirkülasyon içinde problemin çıkmazında tekrarlanan bir döngü oluşmaktadır ve çıkış noktası ancak başka bir problem odaklı terapinin katkısıyla olabilir yanılgısı içine girilmektedir (Bavelas ve diğ., 2013).

\section{Çözüm Odaklı Kısa Süreli Terapinin Temel İlkeleri}

ÇOKST’nin temel ilkeleri şu şekilde sıralanabilir (Berg ve Miller, 1992):

- Danışma sürecinde danışanların patolojik durumlarının merkeze alınması yerine onların zihinsel sağlıklarına odaklanılmaktadır.

- Danışma sürecinde danışanın geçmiş yaşantılarındaki başarılarından ve danışanın var olan potansiyelinden yararlanılmaktadır; danışanın güçlü yönlerinin ortaya çıkarılması ve bunun sonucu olarak problemin çözümü için çözüm yollarını danışanın kendisinin bulması amaçlanmaktadır.

- Danışma sürecinde danışan kendi çözüm yollarını bilen bir uzman olarak görülmektedir. Danışman ise, danışanı yönlendirmek yerine onun problemlerini ve çözüm yollarını öğrenmeye çalışan bir öğrenci konumundadır. 
- Danışma sürecinde probleme odaklanmak yerine çözüme ve çözüm için gerekli olan değişimlere odaklanılmaktadır. Bu yaklaşıma göre değişim başladığı zaman problem kendiliğinden çözülmektedir.

- $\quad$ Danışanın çözüme gidebilmesi için kendisine ait bazı şeyleri değiştirmesi gerekmektedir. Yani, çözümün olabilmesi için değişim gereklidir.

- Danışma sürecinde geçmişe odaklanılması yerine şimdi ve geleceğe odaklanılması gerekmektedir. Danışman, danışanın dikkatini şimdi ve geleceğe çekmekle görevlidir.

- Danışma sürecinde danışmanın danışanın bakış açısını anlayarak onunla problemin çözümü hakkında tartışması, danışanın geçmiş problemlerini nasıl çözdügünü hatırlatması, onun mevcut olan potansiyelini ortaya çıkarmaya çalışması önemlidir (Berg ve Miller, 1992).

\section{Kısa Süreli Terapi}

Günümüzde birçok yaklaşım ve modern anlayış terapiyi ömür boyu ve düzenli bir şekilde alınması gereken bir yardım olarak benimsemiştir. Özellikle modernleşen ve yalnızlaşan toplumlarda danışma yardımı alma oranları gittikçe artmaktadır (Weiten, Hammer ve Dunn, 2014). ÇOKST anlayışında ise, terapi danışanın ihtiyacı olduğu süre kadar devam etmelidir (De Shazer, 1985).

Kısa süreli terapilerin en az uzun süreli terapiler kadar danışanlara fayda sağladığı çalışmalar bulunmuştur (De Shazer, 1985; Plotnik, 2009). ÇOKST uygulaması ve sorularıyla yıllarca sürebilecek bir terapi modeli olarak tasarlanmamıştır (De Shazer ve Dolan, 2012). Danışanların çözüm inşa süreçlerini doğrudan danışma sürecinin temeline alan, sonrasında bunu danışanın problemlerinde nasıl uygulayabileceğini danışanla tartışan bir terapi olduğu için zaman yönünden diğer terapi modellerine göre daha kısa sürelidir.

\section{Çözüm Odaklı Kısa Süreli Terapi Araştırmalarına Uluslararası ve Ulusal Bir Bakış}

Özellikle okullardaki danışmanlık uygulamaları olmak üzere birçok alanda çözüm odaklı kısa süreli terapi hakkında araştırmalar yapılmıştır. Günümüzde kısa süreli terapi uzun süreli terapiye oranla daha fazla tercih edilirken (Meydan, 2013), ÇOKST araştırmalarının da artması kaçınılmazdır. ÇOKST’nin kullanımı genellikle (a) terapötik alanlarda: aile ve çift terapisi, madde bağımlılığı, cinsel istismar, cinsel terapi, yeme bozuklukları, yetişkin akıl sağlığı bozuklukları, şizofreni dahil olmak üzere bireysel, grup terapi çalışmaları; (b) terapötik olmayan alanlarda: sosyal bakım hizmetleri, hapishane toplulukları, eğitim ortamları, iş sistemleri gerçekleşmektedir (Smith, 2010). Dünyadaki önemli ÇOKST çalışmalarını Çözüm Odaklı Kısa Süreli Terapi Derneği üyesi Alasdair Macdonald listelemektedir (Macdonald, 2013). Bu listede 
İngilizce yayınlanan iki meta-analiz, beş sistematik inceleme, 26 rastgele örneklem seçilmiş çalışma (13'ünde ÇOKST diğer terapilere kıyasla daha yararlı bulunmuştur) ve 47 karşılaştırmalı çalışma (38'inde ÇOKST daha başarılıdır) bulunmaktadır. Bu çalışmalar başta öğrenciler olmak üzere bütün yaş gruplarında birçok farklı popülasyonu barındırmaktadır (örneğin: yaşlılar, madde bağımlıları, suçlu insanlar, psikolojik bozukluklara sahip olanlar vs.). Ayrıca İngilizce dili dışındaki dillerde yayınlanan ÇOKST makalelerin sayısı sadece 2012 yılında 100'ü geçmiştir (Macdonald, 2013).

Dünyadaki çalışmalar karşısında sınırlı olarak görünse de Türkiye'de, son yıllarda ÇOKST konusundan birçok değerli çalışma yapılmıştır. Türkiye'de yapılan hemen hemen bütün deneysel çalışmalarda ÇOKST uygulanan deney grubu, kontrol grubuna kıyasla amaç doğrultusunda daha anlamlı oranda olumlu sonuçlar vermiştir. Örnek olarak son ylllarda Türkiye'de yapılan çalışmalara bakıldığında ÇOKST'nin; (a) akran zorbalığını düşürdüğü (Arslan ve Akın, 2016; Çitemel, 2014), öfke kontrolünü olumlu yönde etkilediği yapmaktadır (Siyez ve Tuna, 2014), sosyal fobiyi azalttığı (Ateş ve Gençdoğan, 2017), güvengenlik becerilerini arttırdığı (Ateş, 2015), lise öğrencilerinin okul tükenmişlik sendromlarını azalttığı (Ateş, 2016), depresif belirtileri azaltmada etkili olduğu (Sarı ve Günaydın, 2016), evlilik uyumunu (Baygül ve Rasit, 2016), empatiyi arttırdığı (Karahan, Bakalım ve Yoleri, 2017) ve test kaygısını azalttığı görülmektedir (Bulut, 2010; İşlek, 2006; Sarıcı-Bulut, 2010; Tuna, 2012). Bu araştırmalara ek olarak, ÇOKST'nin daha iyi anlaşılması için farklı popülasyonlarda danışma olarak uygulanmasını inceleyen çalışmalar da bulunmaktadır (Dogan, 1999, 2000; Meydan, 2013). Dogan (1999; 2000) makalelerinde çözüm odaklı kısa süreli terapinin kuramını ve uygulama alanlarını ele alırken; Meydan (2013) ise yaptığı çalışmasında, ÇOKST'in çocuk ve ergen psikolojisi üzerindeki etkisini araştırmıştır.

\section{Çözüm Odaklı Kısa Süreli Terapi Soruları}

Çözüm Odaklı Kısa Süreli Terapin (ÇOKST) uygulamasının temelini sorular oluşturmaktadır. Bu sorular bir denklem içindedir. Sorular, danışanın çözüm inşa etme süreçlerini ortaya çıkarmak, bu süreçlerin nasıl ortaya çıktığını danışanla tartışmak ve bu çözüm inşa etme süreçlerini danışanın hayatındaki diğer problemlerde uygulayabilmesi amacıyla sorulmaktadır. Çözüm odaklı sorular, danışanın problemiyle uzaktan veya yakından bilgi edinmek için kullanılmamaktadır. ÇOKST sorularının dizayn edilme şekilleri, felsefesinin de izin verdiği şekilde, sadece çözüme giden yolları aydınlatmak için kullanılmaktadır (Bannick, 2007; Bavelas ve diğ., 2013).

\section{Mucize Soru}

Berg danışmaların birisinde danışanın bir türlü çözüme dair fikir üretememesi üzerine dayanamayarak "evet, bir mucize oldu ve sorunların çözüldü" diyerek mucize soruyu yaratmışırı (DeJong ve Berg, 1998). Danışanın amacını ortaya çıkartarak belirginleştirmek için kullanılan 
mucize soru De Shazer ve diğer Milwaukee çalışanları tarafından geliştirilerek son halini almıştır (De Shazer ve diğ., 2007):

Diyelim ki bir gece, sen uyurken, bir mucize gerçekleşti ve bu problemin çözüldü (ve probleminin çözüldüğ̈̈nden senin haberin yok) Probleminin çözülddüğ̈̈nü nasıl anlardın? Farklı olan hangi şeyler sana bir mucizenin gerçekleşip, probleminin bittiğini hissettirirdi? (DeJong ve Berg, 1998.

Danışma oturumlarında mucize sorunun sorulması için en uygun zamanın beklenilmesi çok önemlidir (Miller ve Berg, 1996). Danışan ile terapötik ilişki kurmadan bu soruyu sormak, sorunun doğru bir şekilde anlaşılmasından ziyade danışanın geri çekilmesine neden olabilmektedir. İkinci dikkat edilmesi gereken nokta ise; mucize sorunun sorulmasının amac1, mucizenin ne olduğunu ortaya çıkartmak değildir. Mucize sonrası nasıl bir hayatın hayal edildiğini danışanla tartışıp, danışanın nihai hedefinin kendisi için daha belirgin bir hale gelmesine yardımcı olmaktır. Son olarak, mucize soruyu sorarken danışanın kültürel özelliklerine dikkat edilerek, mucize soruyu danışanın anlayacağı şekilde yorumlamak ve yöneltmek gerekebilmektedir (Miller ve Berg, 1996).

\section{Derecelendirme Soruları}

Danışma oturumlarında derecelendirme sorularının kullanılması sırasıyla şu faydaları sağlamaktadır: (a) danışanların danışmaya geldiklerindeki kendi bulundukları noktayı anlamalarını sağlamaktadır, (b) danışanların var oldukları noktaya gelmelerindeki önemli etkenleri ve emeklerini ortaya çıkarmaktadır, (c) danışanların mevcut başarıları üzerine odaklanmaktadır ve (d) gelecek amaçlarını somutlaştırmayı amaçlamaktadır (Bannick, 2007; Bavelas ve diğ., 2013; Sharry, 2017).

1'dan 10'a kadar olan bir ölçekte, 10 problemin tamamen çözülldüğünü, 1 ise çözümün olma ihtimalin hiç olmadı̆̆ını gösteriyor. Bu ölçekte kendinizi hangi rakamda görüyorsunuz? (De Shazer ve Dolan, 2012; Murphy, 2008; Sharry, 2017).

$\mathrm{Bu}$ soruları sorarken dikkat edilmesi gereken noktalar şu şekilde sıralanmaktadır: (a) danışanın verdiği rakamı her zaman başarı olarak algılayıp, bu noktaya nasıl gelebildiğine dikkat çekmek, (b) daha yüksek rakamlara nasıl çıkacağı konusunda danışan ile tartışmak, (c) problemlere odaklanacak sorular sormamak gerekmektedir (De Shazer ve Dolan, 2012). Çözüm odaklı eğitimlerde sorulan en genel soru, danışanın 1 (bir) demesi durumunda nasıl bir yol izleneceğidir. Bu konuda her zaman danışanın çevre desteğinden yararlanılması ve "peki annen (veya arkadaşın) seni hangi rakamda görüyor?" gibi sorular sorulması önerilmektedir. Ayrıca, bu gibi umutsuz görünen durumlarda, danışana danışma sürecinin sonunda ulaşmak istediği rakam sorularak (Örneğin: Peki bugünün sonunda buradan ayrılırken kendinizi hangi rakamda görmek isterdiniz?), aradaki farkın nasıl inşa edilebileceği konusuna danışanın odaklanması sağlanabilir (Bannick, 2007). 


\section{İstisna Soruları}

ÇOKST'de temel olarak, ne kadar nadir olursa olsun başarı içeren istisnalar üzerine çözüm inşa edilmektedir. Bunun yapılmasındaki amacın felsefesini Murphy (2015) şu şekilde açıklamaktadır: "Probleme odaklanırsanız, problem büyür; çözüme odaklanırsanız, çözüm büyür." (s. 115). Bu nedenle danışma sürecinde, danışanın hayatında başardığı ve danışmada bahsetmediği istisnaları ortaya çıkartmak önemlidir (Berg, 1991). Danışma oturumlarında danışanın hayatında yer alan istisnalara yeterli vakit ayırıp, onları detaylandırmak ve sonrasında derecelendirme sorularından yardım alarak danışana çözümü nasıl inşa ettiğini gösterebilmek önemli görülmektedir. Bu sayede danışan kendi kaynaklarının farkına varabilmekte, şimdiki ve gelecekteki problemlerinde daha önceki başarılarını tekrar etmeye çalışabilmektedir (Sklare, 2015). İstisna sorularının örnekleri şunlar olabilir (Sklare, 2015):

Bunun (şikayetin) olmadı̆g veya diğer zamanlara göre daha az olduğu zamanlardan bahseder misin?

Çocuğunu disipline ederken sakin kalmaya en yakın olduğun zamanlardan bahseder misin?

Murhpy (1994) danışma sürecinde, istisna sorularını kullanmak isteyen danışmanlar için beş basamaklı bir süreç önermektedir:

1. Ortaya Çıkarma: İstisna ortaya çıkarılır.

2. Ayrıntıya İnme: Ortaya çıkan istisna hakkında ayrıntılı bilgi alınır.

3. Genişletme: İstisnanın olduğu farklı durumlar bulunmaya çalışılır.

4. Değerlendirme: İstisnaların gerçekçiliği ve diğer ihtiyaç olunan durumlarda nasıl kullanılacağı danışanla değerlendirilir.

5. Destekleme: Danışana bu istisnayı nasıl tekrarlayabileceği ve genişletebileceği konusunda destek verilir (Murhpy, 1994).

\section{Baş Etme Soruları}

Danışanların, hayatlarındaki başarılarını ve çözümlerini ortaya çıkaran ve bunları derinlemesine danışanla tartışılmasına yardım eden sorulara baş etme soruları denilmektedir. Literatür incelendiğinde baş etme sorularının, özellikle ciddi problem durumlarında, bütün yaş grubundaki insanların kabullenme derecelerini arttırdığı görülmektedir (Luthar, 2003). Örnek vermek gerekirse; matematik dersinde başarısız olduğu için danışmaya gelen bir danışana fen dersinde nasıl başarılı olduğunu sormak, fen dersindeki başarı örneğinin hangi durumlarda matematik dersinde kullanabileceğini tartışmak baş etme sorularını oluşturmaktadır. Aynı zamanda aşağıdaki örnek soruda olduğu gibi, depresyonda olduğunu belirten ve hiçbir şey yapmak istemeyen bir danışanı probleme odaklanmak yerine baş etme sorularıyla çözüme dayalı bir danışmaya yönlendirmek önerilmektedir. 
Bu sabah yataktan çıkmayı nasıl başardınız?

Beden dersinde nasll başarll oluyorsunuz?

Bu kadar sorunlu bir patrona rağmen, hala işinizde nasıl başarll olabiliyorsunuz? (Murphy, 2008).

Şimdi ve geleceğe odaklanan ÇOKST'de baş etme soruları, danışanın geçmişteki başarılarının şimdi ve gelecekte ona nasıl katkı sağlayacağına odaklanmaktadır. Danışma sürecinde geçmişteki başarıların detaylandırılması, üzerinde durulması ve hangi durumlarda tekrarlanabildiğinin öğrenilmesi kadar, danışanın hayatına bu başarıların şimdi ve gelecekte nasıl dahil edilebileceğinin de tartışılması önemsenmektedir (Murphy, 2015).

\section{Çözüm Odaklı Kısa Süreli Terapiye Yönelik Eleştiriler}

Literatürde ÇOKST yaklaşımı için bazı eleştirilerin var olduğu görülmektedir. Problem odaklı yaklaşımlarla kıyaslandığında, ÇOKST’nin danışma sürecinde probleme odaklanmaması ve kullandığı sorularla oluşturduğu prosedür ile teknikler araştırmacılar tarafindan eleştirilerin temelini oluşturmaktadır. Bu eleştirilerden birincisi, ÇOKST'de probleme dair detaylandırıcı sorular soramamanın psikologlar ve psikolojik danışmanlar için mesleki yetersizlik duygusu yarattığı ve danışanların duygularını açığa vuramadıkları için terapinin başarı oranının diğer yaklaşımlara göre daha düşük olabileceğidir (Lipchik, 1994). İkinci olarak ise, birçok danışma modelinin aksine ÇOKST sürecinde değişimin ortaya çıkabilmesi için danışanın bilinç ve kavrayış becerilerinin yeteri kadar kullanılmamasıdır (O'Hanlon ve Weiner-Davis, 1989). ÇOKST yaklaşımının eleştirildiği bir diğer nokta ise, psikolojik danışman ile danışan arasındaki ilişkiyi yeterince önemsememesidir (Lipchik, 1994). Bir diğer eleştiri ise, ÇOKST yaklaşımının oldukça basit olarak nitelendirilmesi ve her danışanın kendi hedeflerini belirleme ve bu hedeflere ulaşma becerisine sahip olamayabileceğidir (Clark-Stager, 1999). Son olarak ise, ÇOKST yaklaşımını benimseyen danışmanların problemi ve problemin nedenlerini önemsememesi sadece problemin belirtilerine odaklanmaları, uzun süreli bir etki yaratmayacağı düşünüldüğü için eleştirilmektedir (Fennell, 1997).

\section{Tartışma}

ÇOKST kullanan terapistler, danışanları kendi hayatlarında yaşadıkları problemlerden dolayı kendi istekleriyle veya zorla danışmaya gelmiş olsalar da danışanlarının kendi iç güçlerine ve yaşamlarındaki başarılarına odaklanarak, onların problemlerini çözmelerini sağlamaktadırlar. Simon ve Nelson (2005), ÇOKST sürecinde danışanların bazılarının danışmayı başarılı bulmasının nedeninin, onların problemleri hakkında konuşabilmesi olduğunu ortaya çıkarmıştır. Danışma sürecinde çözüm inşa edilmesi hakkında konuşulması, danışanların dolaylı olarak kendi problemlerini değerlendirmelerine yardımcı olmaktadır. ÇOKST süreci boyunca problemin içselleştirilmesi yerine problemden çıkış noktası ve çözümün nasıl sağlanacağı üzerine 
tartışılmaktadır. Örneğin, dışarı çıkma korkusu olan bir danışanın neden dışarı çıkma korkusu olduğunu bilmek ve bu korkunun temellerine inmek gerekli değildir (De Shazer, 1985). Danışma sürecinde, danışanın en son ne zaman dışarı çıkabildiği, bunu nasıl başardığı, dışarı çıkabildiğindeki yaşadığı duyguları ve bunu nasıl tekrarlayabileceği tartışılmaktadır.

Diğer terapi modelleri gibi ÇOKST'nin de sınırlılıklarının ve limitlerinin olmasının yanında, yanlış bilinen noktaları da bulunmaktadır. Bunlardan en önemlisi, ÇOKST'nin travma, intihar eğilimi, cinsel taciz gibi hassas ve ciddi terapi ihtiyaçlarında kullanılmasının uygun olmayacağı düşüncesidir (Bannick, 2007). Literatür incelendiğinde, ÇOKST'nin bu tür terapi ihtiyaçlarında da başarılı olduğu görülmektedir (Bannick, 2007; Rowan ve O'hanlon, 1999; Gingerich ve Peterson 2013). Ek olarak, ÇOKST diğer terapi modellerinin aksine belirtilen terapi ihtiyaçlarında danışanın yaşadığı zorlukları tekrar yaşamasını engellemektedir ve onun kendisini başarısız bir birey olarak görmesine neden olmamaktadır. Örneğin, başarısız intihar denemesi yapmış bir danışana, intihar teşebbüsü hakkında soru sormak yerine, intihar sonrasında nasıl hayatta kaldığını sormak ve irdelemek, onu hayata bağlayan sosyal ve bireysel kaynakları tespit etmek çözümü inşa edebilmektedir (Bannick, 2007).

\section{Çözüm Odaklı Kısa Süreli Terapinin Uygulanabilirliği ve Alana Katkıları}

ÇOKST'nin Türkiye'de psikolojik danışmanlık alanında kullanılmasının uygunluğundan ve yararlı olabileceğinden bahsedilebilir. ÇOKST, kuramsal çerçevesi ve uygulama yöntemi ile zaman, hesap verilebilirlik ve kültürel açılarından psikolojik danışmanlar ve terapistler için avantajlar içermektedir.

Türkiye'de, psikolojik danışmanlık özel sektörde gelişmekte olmasına rağmen sınırlıdır ve çoğunlukla psikolojik danışmanlık hizmeti okullardaki rehber öğretmenler ve psikolojik danışmanlar tarafindan verilmektedir (Arslan ve Sommers Flanagan, 2018; Poyrazlı, Doğan ve Eskin, 2013). Okullarda çalışan psikolojik danışmanların yoğun programları nedeni ile zamanı verimli kullanmaları önemlidir. Ayrıca, öğrencilerin psikolojik danışmanlık hizmetinden yararlanmak istemeleri halinde derslerinden, ihtiyaç teneffüslerinden veya öğle yemeklerinden vazgeçmeleri gerekebilmektedir. Bu yüzden okul psikolojik danışma servisinin uzun süreli terapi hizmeti sunması, hem psikolojik danışmanlar için zaman problemi yaratabilmekte hem de ögrencilerin okuldaki akranlarına oranla akademik ve sosyal imkanlardan daha az faydalanmasına neden olabilmektedir. Özellikle, "ülkemizde okul psikolojik danışman sayısının sınırlı olması, psikolojik danışman başına düşen öğrenci sayısının yüksek olması" (Hamamcı, Bacanlı ve Doğan, 2013, s. 295), okul psikolojik danışmanının zamanını verimli kullanması gerekliliğinin en önemli nedenlerindendir. Bu açıdan, ÇOKST hem kısa süreli uygulamasıyla hem de çözüm inşa etmeye yönelik hızlı pratiği sayesinde okullarda psikolojik danışmanlara zaman tasarrufu sağlayarak öğrencilere faydalı olabilir.

İkinci olarak, Türkiye'de psikolojik danı̧̧manlık nicelik olarak son yıllarda hızlı bir gelişme göstermiştir ve psikolojik danışmanların yeterlilikleri ile çalışmalarındaki verimlilik 
önem kazanmıştır (Arslan ve Sommers Flanagan, 2018; Güven, 2009). Psikolojik danışmanların hangi kuramları, nasıl ve hangi çerçevede uyguladıkları konusunda bir belirsizlik bulunmaktadır ve bunu takip edecek etik ve yasal bir mekanizma henüz oluşturulamamıştır. Ancak psikolojik danışma hizmetlerinin verimliliğinin ortaya konması gerekmektedir (Terzi, Ergüner Tekinalp ve Leuwerke, 2011) ve danışanlara sunulan psikolojik danışma seçeneğini değerlendirme şansı verilmelidir (Çetinkaya, 2015). Örneğin test kaygısı yaşayan bir öğrenciye, bir psikolojik danışmanın hangi terapi modelini kaç hafta süreyle nasıl uygulayıp, terapinin sonuçlarını raporlaştırdıktan sonra, psikolojik danışmanın verimliliğine dair bilgilendirme yapılması gerekmektedir. ÇOKST, bilişsel ve kanıta dayalı terapi modelleri gibi, psikolojik danışmanların uygulama yöntemleri ve aşamalarını detaylı bir şekilde ortaya koyabilmelerine olanak tanımaktadır. Hesap verilebilirlik açısından, ÇOKST uygulamaları psikolojik danışmanlara bir standart getirebilir. Bu sayede, psikolojik danışmanın hedefleri, aşamaları ve sonuçları 'hesap verilebilirlik' açısından raporlanabilir ve standartlaştırılabilir.

Üçüncü olarak, ÇOKST danışan merkezli bir yaklaşım olduğu için kültürel farklılıklara karşı hassastır ve kolayca uyarlanabilmektedir. Danışanın bireysel ve toplumsal kültürüne uygun bir çözüm, danışanın önderliğinde profesyonel bir terapötik ilişki ile inşa edilmektedir. $\mathrm{Bu}$ nedenle ÇOKST psikolojik danışma alanında kültürel beklentilere cevap verebilir. Ayrıca, birçok dini, etnik ve kültürel farklılığa sahip olan Türkiye'de, çok kültürlü psikolojik danışmanın temel prensipleri (bilgi, yetenek, farkındalık ve hak savunuculuğu) ÇOKST planlaması içinde özümsenerek uygulanabilir.

Sonuç olarak, terapi sürecinde terapi tekniklerinin etkisi Corsini ve Wedding'in (2012) Modern Psikoterapiler kitabında belirttiği gibi sınırlıdır. Bu kapsamda, ÇOKST'de diğer terapi yöntemleri gibi danışanın uyguladığı teknik toplamda seansın başarısına yüzde $15^{\prime}$ lik bir etki yapabilmektedir (Asay ve Lambert, 1999). Aynı zamanda, danışmanların mesleki yetkinliği psikolojik danışma sürecinin başarıya ulaşma yüzdeleri ile doğru orantılıdır. Diğer psikolojik yaklaşımlarda olduğu gibi, ÇOKST ile etkili danışma sürecinin yaratılabilmesi için, iyi eğitim almış ve deneyimli terapistlerin, danışanın iç dünyasına inebilmesi, danışanla güçlü terapötik ilişki kurabilmesi ve danışanın geleceğe ümitle bakabilmesi gerekmektedir.

\section{Kaynakça}

Arslan, N., \& Akın, A. (2016). Çözüm odaklı kısa süreli grupla psikolojik danışmanın lise öğrencilerinin akran zorbalığına etkisi. Sakarya University Journal Of Education, 6(1), 72-84. doi:http://dx.doi.org/10.19126/suje.62580

Arslan, Ü. \& Sommers-Flanagan, J. (2018), The New Stage of the Turkish Counseling System: Explosive Growth (2000 to the Present). Journal of Multicultural Counseling and Development, 46: 115-128. doi:10.1002/jmcd.12096

Asay, T. P., \& Lambert, M. J. (1999). The empirical case for the common factors in therapy: Quantitative findings. In M. A. Hubble, B. L. Duncan, \& S. D. Miller (Eds.), The heart and soul of change: What works in therapy (pp. 23-55). Washington, DC, US: American Psychological Association. doi: http://dx.doi.org/10.1037/11132-001 
Ateş, B. (2015). Üniversite öğrencilerinin güvengenlik becerileri üzerinde çözüm odaklı grupla psikolojik danışmanın etkisi. Mersin Üniversitesi Eğitim Fakültesi Dergisi, 11 (3). doi: http://dx.doi.org/10.17860/efd.84626

Ateş, B. (2016). Effect of solution focused group counseling for high school students in order to struggle with school burnout. Journal of Education and Training Studies, 4(4), 27-34. doi:http://dx.doi.org/10.11114/jets.v4i4.1254

Ateş, B., \& Gençdoğan, B. (2017). Analyzing the effects of solution focused group psychological counseling upon university students' coping with social phobia. İn̈nü Üniversitesi Eğitim Fakültesi Dergisi, 18 (1), 188-203. doi: 10.17679/inuefd.306513

Bannick, B. P. (2007). Solution focused brief therapy. Journal of Contemporary Psychotherapy. 37(2):87-94. doi: 10.1007/s10879-006-9040-y

Bavelas, J., De Jong, P., Franklin, C., Froerer, A., Gingerick, W., \& Kim, J. (2013). Solution focused therapy treatment manual for working with individuals (2nd version). Solution Focused Brief Therapy Association.

Baygül, Ş., \& Raşit, A. V. C. I. (2016). Çözüm odaklı kısa süreli aile danışmanlığı kuramına dayalı olarak geliştirilen evlilik programının çiftlerin evlilik uyumlarını artırmadaki etkisi [the effects of marital program developed in accordance with solution focused brief family counseling]. Mustafa Kemal Üniversitesi Sosyal Bilimler Enstitüsü Dergisi, 13(36).

Berg, I. K., \& Miller, S. D. (1992). Working with the problem drinker: A solution focused approach. New York: Norton.

Bulut, S. S. (2010). İlköğretim ikinci kademe öğrencilerinin sınav kaygıları, saldırganlık eğilimleri ve problem çözme becerilerindeki yetersizliklerin sağaltımında grupla çözüm odaklı kısa terapinin etkileri. Gazi University Journal of Gazi Educational Faculty (GUJGEF), 30(2).

Clark-Stager, W. (1999). Using Solution-Focused Therapy Within an Integrative Behavioral Couple Therapy Framework: An Integrative Model. Journal Of Family Psychotherapy, $10,27-47$.

Corsini, R. J. \& Wedding D. (2012). Modern Psikoterapi Teknikleri. İstanbul: Kaknüs Yayınları: Psikoloji Dizisi

Çetinkaya, R. (2015). Psikolojik danışmanlıkta meslek etiği ve yasal konular. Aktüel Yayınları Alfa Akademi.

Çitemel, N. (2014). Çözüm odaklı kısa süreli grupla psikolojik danışmanın lise öğrencilerinin akran zorbalığına etkisi. Yayınlanmamış Doktora Tezi. Sakarya Üniversitesi, Eğitim Bilimleri Enstitüsü.

De Jong, P. \& Berg, I. K. (2002). Interviewing For Solution. Pacific Grove, CA: Brooks/Cole.

De Jong, P., \& Berg, I. K. (1997). Interviewing for solutions. Pacific Grove California: Brooks/Cole.

De Shazer, S. (1985). Keys to solution in brief therapy. New York: Norton. 
De Shazer, S., \& Dolan, Y. (2012). More than miracles: The state of the art of solution-focused brief therapy. Routledge.

De Shazer, S., Dolan, Y.M., Korman, H., Trepper, T.S., McCollum, E.E., \& Berg, I.K. (2007). More than miracles: The state of the art of solution focused therapy. New York: Haworth Press.

Doğan, S. (1999). Çözüm odaklı kısa süreli terapi: Kuramsal bir inceleme. Türk Psikolojik Danışma ve Rehberlik Dergisi, 2 (12), 28-38.

Doğan, S. (2000). Okul psikolojik danışmanları için yeni ve pratik bir yaklaşım: çözüm-odaklı kısa süreli psikolojik danışma. Eğitim ve Bilim Dergisi, 25 (116),59-66.

Eriksen, K., \& McAuliffe, G. (2003). A measure of counselor competency. Counselor Education and Supervision, 43(2), 120-133.

Fennell, D. L. (1997). Counseling Families: An Introduction to Marriage and Family Therapy. Denver: Love Publishing.

Gingerich, W. J., \& Peterson, L. T. (2013). Effectiveness of Solution-Focused Brief Therapy A Systematic Qualitative Review of Controlled Outcome Studies. Research on Social Work Practice, 23(3), 266-283.

Groot, D. S. (2002). Shifting Gears: An Integration Of Solution - Focused Therapy And Experiential Therapy in Couples Counselling. University of Manitoba,Master Thesis.

Güven, M. (2009). Milli Eğitim Bakanlığı müfettişlerinin okul rehberlik hizmetleri ve denetimiyle ilgili görüşleri. Uluslararası. Sosyal Araştırmalar Dergisi [The Journal of International Social Research], 2/9.

Hamamc1, Z., Bacanl1, F., \& Doğan, H. (2013). İlköğretim ortaöğretim ve üniversite öğrencilerinin mesleki ve eğitsel kararlarini etkileyen faktörlerin incelenmesi. Elektronik Sosyal Bilimler Dergisi, Cilt:12 Sayl:44 (284-299)

Hoyt, M. F. \& Berg, I. K. (1998). Solution-Focused Couple Therapy. In M.F. Hoyt (Ed)., The handbook of Constructive therapies; Innovative approaches from leading practitioners (314-340). San Francisco: Joney-Bass Publishers.

İslek, M. (2006). Çözüm odaklı yaklaşımlara göre düzenlenmiş sınav kaygısıyla başa çıkma eğitim programının üniversiteye hazırlanan öğrencilerin sınav kaygısı düzeylerine etkisi. Yayınlanmamış yüksek lisans tezi, Hacettepe Üniversitesi, Sosyal Bilimler Enstitüsü.

Karaca, R., \& İkiz, F. E. (2014). Psikolojik danışma ve rehberlikte çağdaş bir anlayış. Nobel Yayınları. Ankara

Karahan, F., Bakalım, O., \& Yoleri, S. (2017). Solution focused thinking and empathy in education faculty students [Eğitim fakültesi öğrencilerinde çözüm odaklı düşünme ve empati] Journal of Human Sciences, 14(4), 4383-4392. doi:https://doi.org/10.14687/jhs.v14i4.5024

Lipchik, E. (1994). The Rush to Be Brief. Family Therapy Networker, 18 (2), 35-39.

Luthar, S. S. (Ed.). (2003). Resilience and vulnerability: Adaptation in the context of childhood adversities. New York: Cambridge University Press. 
Macdonald, A.J. (2013). Evaluation list. Erişim Tarihi: 05.10.2017 http://sfbta.org/PDFs/researchDownloads/SFT.pdf

Meydan, B. (2013). Çözüm odaklı kısa süreli psikolojik danışma: okullardaki etkililiği üzerine bir inceleme. Türk Psikolojik Danışma ve Rehberlik Dergisi, 4(39),120-129.

Miller, S. D., \& Berg, I. K. (1996). The miracle method: A radically new approach to problem drinking. WW Norton \& Company.

Murphy, J. J. (2015). Solution-focused counseling in schools. New York: John Wiley \& Sons.

Murpy, J. J. (1994). Working with what works: A solution-focused approach to school behavior problems. School Counselor; 42, 59-65.

O'Hanlon, W .H., \& Weiner-Davis, M. (1989). In Search Of Solution: A New Direction In Psychotherapy. New York: Guilford.

Poyrazlı, S., Doğan, S., \& Eskin, M. (2013). Counseling and psychotherapy in Turkey: Western theories and culturally inclusive. R. Moodley, U. P. Gielen, \& R. Wu (Eds.), Handbook of Counseling and Psychotherapy in an International Context (pp. 404-414). Routledge.

Plotnik, R. (2009). Psikolojiye Giriş, (T. Geniş çev.), Kaknüs yayınları, İstanbul.

Rowan, T., O'Hanlon, B., \& Daroff Jr, R. B. (1999). Solution-oriented therapy for chronic and severe mental illness. New York: John Wiley \& Sons.

Sarı, E., \& Günaydın, N. (2016). Effectiveness of solution-focused coping with depression training on depression symptoms. Anatolian Journal of Psychiatry, 17(5), 369-375.

Sarıcı-Bulut, S. (2010). İlköğretim ikinci kademe öğrencilerinin sınav kaygıları, saldırganlık eğilimleri ve problem çözme becerilerindeki yetersizliklerin sağaltımında grupla çözüm odaklı kısa terapinin etkileri, Gazi Üniversitesi Ĕ̈itim Fakültesi Dergisi, 30(2), 325-356.

Sharry, J. (2017). Çözüm Odaklı Grupla Psikolojik Danışma, (D. M. Siyez, Y. Soylu, Ü. Arslan, E. Esen, Tuba Bağatarhan çev.). Nobel Yayınları, Ankara.

Simon, J., \& Nelson, T. (2005). Results of last session interviews in solution focused brief therapy: Learning from the clients. Journal of family psychotherapy, 15(4), 27-45.

Sirles, E. A., Lipchik, E., \& Kowalski, K. (1993). A Consumer's Perspective On Domestic Violence Interventions. Journal of Family Violence, 8(3), 267-276.

Siyez, D. M., \& Tan Tuna, D. (2014). Lise Öğrencilerinin öfke kontrolü ve iletişim becerilerinde çözüm odaklı psiko-eğitim programının etkisi. Türk Psikolojik Danışma ve Rehberlik Dergisi, 5(41), 11-22. doi:http://dx.doi.org/10.17066/pdrd.57097

Sklare, G. B. (2015). Çözüm Odaklı Kısa Süreli Psikolojik Danışma, (D. M. Siyez, çev.). Pegem Yayınları, İstanbul.

Smith, S. (2010). A preliminary analysis of narratives on the impact of training in solutionfocused therapy expressed by students having completed a 6-month training course. Journal of Psychiatric and Mental Health Nursing, 17,105- 110. 
Terzi, Ş, Ergüner Tekinalp, B., \& Leuwerke, W. (2011). The evaluation of comprehensive guidance and counseling programs based on school counseling and guidance services model by school counselors. Pegem Ĕ̆itim ve Öğretim Dergisi, 1(1), 51-60. https://doi.org/https://doi.org/10.14527/C1S1M6

Tuna, D. (2012). Çözüm odaklı kısa süreli yaklaşıma dayalı öfke kontrolü eğitim programının lise öğrencilerinin öfke kontrolü ve iletişim becerileri düzeylerine etkisi. Yayınlanmamış Yüksek Lisans Tezi.. İmir: Dokuz Eylül Universitesi.

Watzlawick, P., Weakland, J. H., \& Fisch, R. (1974). Change: Principles of problem formation and problem resolution. New York: Norton.

Weiten, W., Dunn, D. S., \& Hammer, E. Y. (2014). Psychology applied to modern life: Adjustment in the 21 st century. Cengage Learning.

\section{Extended Abstract}

Solution Focused Brief Therapy (SFBT) has become one of the modern therapy techniques after it was established in the United States. Unlike other therapy techniques, the whole method had been developed by the inductive method. Watzlawick, Weakland, and Fisch's (1974) idea that "it is not always necessary to examine the problem to make solution trials" was developed later on by De Shazer, Berg, and their colleagues. This article refers to the historical and philosophical stance of the solution-focused brief therapy and explains the crucial points to be considered in practice for counselor candidates, counselors, and faculty members in the field of counseling. The application SFBT is a completely different approach than other problemfocused approaches. Problems may occur when SFBT model is combined with other problemfocused models.

\section{Philosophy of Solution Focused Brief Therapy}

The philosophy of SFBT is important. Since all counselors and psychologists are trained based on problem-oriented therapy, focusing on solutions only creates many difficulties for them. In the SFBT, the counselor does not (a) reflect or summarize, (b) ask questions to detail, and (c) give positive reinforcement for problems. The counselors ignore and do not take an action for problems unless it relates to a solution or a success.

The basic principles of SFBT are:

1. If it is not broken, do not fix it.

2. If it works, do more.

3. If it does not work, do something different.

4. Small steps can lead to big changes.

5. The solution does not have to be directly related to the problem.

6. The language needed to be used to reach the solution is different from the need to describe the problem. 
7. There will always be exceptions, there are always exceptions.

8. The future can be created and discussed.

\section{The Importance of Solution Focused Brief Therapy Philosophy}

Applying SFBT without internalizing its own philosophy can be only asking solutionfocused therapy questions in a problem-focused structure. SFBT can be only successful in counseling practice: (a) by understanding clients in a solution-oriented perspective and (b) by discussing with clients how they created solutions for their problems in the past, and how they could repeat these solutions in the future.

\section{Brief Therapy}

In the SFBT approach, therapy only should be continued as long as necessary. Several studies show that short-term therapies are as beneficial as well as at least long-term therapies.

\section{Solution Focused Brief Therapy Questions}

The fundamentals of SFBT practice are questions. These questions are in an equation and are only asked about how to (a) expose the process of building solutions, (b) discuss solutions with clients, and (c) implement solutions in other problems of clients.

\section{Miracle Question}

In one of Berg's counseling session, she created a miracle question by saying "yes, it was a miracle, and the problems were resolved" by not being able to produce an idea of a solution. De Shazer and other Milwaukee employees developed and established the miracle question.

"Let's say, tonight night, while you were sleeping, a miracle happened and you figured out this problem was solved (and you don't know that your problem was solved). What makes you feel a miracle happened and your problem is over?"

\section{Scaling Questions}

The scaling questions provide that clients (a) understand the point where they come to the counseling, (b) reveal the important factors and labor of their arrival, (c) focus on these present achievements, and (d) aim to embody their future goals.

"On a scale of 1 to 10, it shows that 10 problems are completely solved, and 1 is no chance of resolution. On what scale do you see yourself at this scale?"

\section{Exception Questions}

In SFBT, it is important for counselors to explore exceptions that clients already have lived in their lives. These exceptions could be reviewed and detailed with grading questions. 
"Could you talk about times, which your problems occur less?"

"Could you talk about time, when you are closest to being calm while disciplining your child?"

\section{Coping Questions}

Coping questions reveal success and solution pathways of the clients, when they face with their own problems.

"How did you manage to get up this morning?"

"Despite such a troubled boss, how do you still succeed at your job?"

\section{Discussion}

Either clients who may come by their own desires or by someone's forcible consultation due to problems, which they have experienced in their own lives, therapists who use SFBT approach focus on clients' strengths and success. During the SFBT, counselors are looking forward to get out of talking problems and finding pathways of building solutions.

Limits of the SFBT are similar to other therapy approaches. A particularly well-known misunderstanding is that SFBT is would not be sufficient for sensitive and serious therapy needs such as trauma, suicidal tendencies, and sexual harassment. However, it has been found that SFBT is successful in this type of therapy needs as well.

As a result, a well-trained and experienced therapist can build an effective counseling session with SFBT. If a therapist establishes a strong therapeutic relationship with clients, understands clients' needs, and encourages their clients to have hope for the future, the therapy could be successful. 